\title{
A study of aspiration cytology of various thyroid lesions and histopathological correlation
}

\author{
Venu Anand ${ }^{1}$, S. Selvi ${ }^{2}$, B. Pushpa ${ }^{3}$ \\ ${ }^{1}$ Dr. Venu Anand, Associate Professor of Pathology, Govt. Royapettah Hospital, Kilpauk Medical College, \\ Chennai, ${ }^{2}$ Dr. S. Selvi, Assistant Professor, Govt Kilpauk Medical College, Chennai, ${ }^{3}$ Dr. B. Pushpa, Associate \\ Professor of Pathology, Govt, Kilpauk Medical College, Chennai, all authors are affiliated with the Dr. M.G.R \\ Medical University, Chennai, Tamil Nadu, India.
}

Address for Correspondence: Dr. S. Selvi, Assistant Professor, Govt Kilpauk Medical College, Chennai, Email:dr.selvi24@gmail.com

\begin{abstract}
Background: Thyroid swelling is one of most common neck swelling encountered in clinical practice. Fine needle aspiration cytology (FNAC) is a reliable preoperative screening test to differentiate between benign and malignant lesions which helps in proper management of patient and avoiding unnecessary surgeries. Aims and Objectives: The present study was to evaluate various lesions of thyroid and classify them according to the Bethedsa system of reporting of thyroid cytopathology (TBSRTC) and to correlate FNAC with histopathology wherever possible. Materials and Methods: This study is a retrospective study of 225 cases of thyroid swelling conducted from May 2016 to April 2017 in the department of pathology, Government Royapettah Hospital, Kilpauk Medical College, Chennai. FNAC results were correlated with histopathological diagnosis wherever surgery was done. Results: This study includes 225 cases. Out of 225 cases of FNAC of thyroid lesions, 213 satisfactory cases were obtained. Maximum cases were benign lesion 233 cases (93.3\%), malignant cases were $12(5.3 \%)$ and 12 cases were unsatisfactory (5.3\%) with diagnostic accuracy 99\%, sensitivity 99\% and specificity $100 \%$ Conclusion: FNAC is an effective tool for diagnosing various thyroid lesions as it is safe, cost effective and initial diagnostic modality that avoids unwanted surgeries.
\end{abstract}

Key words: Bethedsa, FNAC, Thyroid, Histopathology.

\section{Introduction}

Thyroid gland is unique among endocrine glands which is easily accessible for direct examination. It is subjected to varying physiological and pathological disturbances such as developmental, inflammatory, hyperplastic and neoplastic. Most common clinical presentation is thyroid nodule. Because of superficial location of the gland, it can be easily subjected to fine needle aspiration cytology (FNAC). As a result of which screening test can be done effectively for thyroid lesions and avoid unwanted invasive procedures. The diagnosis of thyroid lesions using FNAC was first reported by Martin and Ellis in 1930. The incidence of thyroid nodule ranging from $4-7 \%$ of population $[1,2]$. Most of the nodules are non-neoplastic and

\footnotetext{
Manuscript received: $5^{\text {th }}$ November 2017

Reviewed: $15^{\text {th }}$ November 2017

Author Corrected: $24^{\text {th }}$ November 2017

Accepted for Publication: $29^{\text {th }}$ November 2017
}

Only $<5 \%$ are malignant. The main goal of evaluating these nodules by FNAC is to identify nodules which are benign or malignant with the help of effective FNAC screening unnecessary thyroidectomy can be avoided for benign lesions $[3,4]$. The aim is to ascertain the diagnostic accuracy of FNAC in various thyroid lesions using TBSRTC (The Bethedsa system for reporting thyroid cytology) and its correlation with histopathological examination for early and definitive diagnosis which would also help in avoiding unnecessary surgeries.

\section{Materials and Methods}

The present study was a Retrospective study was conducted in the department of pathology in Government Royapettah hospital, Kilpauk Medical 
College, Chennai from March 2016 to June 2017 to determine the diagnostic accuracy of FNAC for thyroid lesions.

A total of 225 cases were studied. Inclusion criteria included all types of thyroid lesions and nonpalpable lesions studied through USG guided FNAC. Exclusion criteria was all swellings arising from skin and surrounding structure of thyroid gland and children below 10 years.

Before starting FNAC explain the procedure to patient and take a consent and then FNAC is done.
Original Research Article

Needles commonly used are 22-24 gauge, under all aseptic precautions needle is introduced attached with $10 \mathrm{ml}$ disposable syringe, with minimal negative pressure material is aspirated and smears are prepared and fixed in 95\% ethanol and stained by hematoxylene and eosin. FNAC was reported following TBSRTC 2007 Bethedsa Classification into I-Non diagnostic or unsatisfactory; II- Benign, III- Atypia of undetermined significance (AUS) or follicular lesion of undetermined significance; IVFollicular neoplasm or suspicious for a follicular neoplasm; V - Suspicious for malignancy; VIMalignant categories. [5]

\section{Results}

The present study included a total of 225 patients of various thyroid lesions. The age ranging from 10 years to 81years with a mean age of $43.24 y$ ys. Females were 178 and males were 35 with a female: male ratio of 5.1:1. [Table1]Aspirate with low yield or poorly stained smears were taken as unsatisfactory.

For satisfactory specimen the criteria was at least 6 groups of benign follicular cells and each group should be composed of at least 10 cells. Aspirates classified as benign - included colloid goiter, hyperplastic nodule of nodular colloid goitre, hashimotos thyroiditis, lymphocytic thyroiditis and cysts of thyroglossal duct.

Suspicious smear - included are of follicular neoplasm and hurthle cell neoplasm. Benign lesion comprised the maximum number of cases 191(85\%), followed by cases 10 (4.44\%) follicular neoplasm and suspicious of malignancy (IV and V).

Table-1: Thyroid Gland Lesions According to Sex Distribution.

\begin{tabular}{|c|c|c|c|c|c|c|}
\hline Sex & $\begin{array}{c}\text { Non neoplastic non } \\
\text { inflammatory } \\
\text { lesions }\end{array}$ & $\begin{array}{c}\text { Non neoplastic } \\
\text { inflammatory } \\
\text { lesions }\end{array}$ & $\begin{array}{c}\text { Neoplastic } \\
\text { benign } \\
\text { lesions }\end{array}$ & $\begin{array}{c}\text { Neoplastic } \\
\text { maligant } \\
\text { lesions }\end{array}$ & Total & Percentage (\%) \\
\hline Male & 30 & 0 & 1 & 4 & 35 & $16.4 \%$ \\
\hline Female & 117 & 44 & 9 & 8 & 178 & $83.6 \%$ \\
\hline Total & $\mathbf{1 4 7}$ & $\mathbf{4 4}$ & $\mathbf{1 0}$ & $\mathbf{1 2}$ & $\mathbf{2 1 3}$ & $\mathbf{1 0 0 \%}$ \\
\hline
\end{tabular}

Table-2: Showing Age \& Sex distribution of cases in different subtypes of Bethesda Classification.

\begin{tabular}{|c|c|c|c|c|c|c|c|c|c|c|c|c|}
\hline \multicolumn{13}{|c|}{ Cytological Diagnostic Category } \\
\hline \multirow{2}{*}{$\begin{array}{c}\text { Age Group } \\
\text { (Years) }\end{array}$} & \multicolumn{2}{|c|}{$\mathrm{I}$} & \multicolumn{2}{|c|}{ II } & \multicolumn{2}{|c|}{ III } & \multicolumn{2}{|c|}{ IV } & \multicolumn{2}{|c|}{$\mathrm{V}$} & \multicolumn{2}{|c|}{ VI } \\
\hline & M & $\mathrm{F}$ & M & $\mathrm{F}$ & $\mathrm{M}$ & $\mathrm{F}$ & M & $\mathrm{F}$ & M & $\mathrm{F}$ & $\mathrm{M}$ & $\mathrm{F}$ \\
\hline $10-20$ & 1 & 1 & 4 & 8 & 0 & 0 & 0 & 0 & 0 & 0 & 0 & 0 \\
\hline $21-30$ & 1 & 2 & 3 & 26 & 0 & 1 & 0 & 1 & 0 & 0 & 0 & 1 \\
\hline $31-40$ & 0 & 3 & 9 & 40 & 0 & 0 & 0 & 1 & 0 & 1 & 0 & 2 \\
\hline $41-50$ & 0 & 3 & 6 & 48 & 1 & 1 & 0 & 0 & 1 & 1 & 0 & 1 \\
\hline $51-60$ & 0 & 0 & 4 & 23 & 0 & 0 & 0 & 1 & 1 & 1 & 1 & 0 \\
\hline$>60$ & 1 & 0 & 4 & 16 & 0 & 2 & 0 & 2 & 0 & 0 & 1 & 1 \\
\hline \multirow[t]{3}{*}{ Total } & \multicolumn{2}{|c|}{12} & \multicolumn{2}{|c|}{191} & \multicolumn{2}{|c|}{5} & \multicolumn{2}{|c|}{5} & \multicolumn{2}{|c|}{5} & \multicolumn{2}{|c|}{7} \\
\hline & \multicolumn{2}{|c|}{5.33} & \multicolumn{2}{|c|}{84.89} & \multicolumn{2}{|c|}{2.22} & \multicolumn{2}{|c|}{2.22} & \multicolumn{2}{|c|}{2.22} & \multicolumn{2}{|c|}{3.11} \\
\hline & \multicolumn{2}{|c|}{34.16} & \multicolumn{2}{|c|}{45.82} & \multicolumn{2}{|c|}{58} & \multicolumn{2}{|c|}{49} & \multicolumn{2}{|c|}{47} & \multicolumn{2}{|c|}{46.43} \\
\hline
\end{tabular}


Table- 3: Benign \& malignant lesions of thyroid.

\begin{tabular}{|c|c|c|c|}
\hline & Unsatisfactory & \multicolumn{2}{|c|}{ Satisfactory } \\
\hline Number of cases & 12 & 201 & 12 \\
\hline$\%$ & 5.3 & 93.4 & 5.3 \\
\hline
\end{tabular}

Table-4: Comparison of results of present study with the previous studies.

\begin{tabular}{|c|c|c|c|c|}
\hline Study & Year & Sensitivity & Specificity & Accuracy \\
\hline Gupta M [3] & 2010 & 80.0 & 86.6 & 84.0 \\
\hline Prakash HM [17] & 2011 & 66.7 & 98.4 & 95.7 \\
\hline Sengupta A [18] & 2011 & 90.0 & 100 & 98.9 \\
\hline Esmaili HA [8] & 2012 & 91.6 & 100 & 97.0 \\
\hline Ranjan Aggarwal[19] & 2015 & 96.7 & 100 & 97.0 \\
\hline Present Study & 2017 & $99 \%$ & $100 \%$ & 99.0 \\
\hline
\end{tabular}

The patients mean age in the malignancy and the suspicious for malignancy category was higher as compared to that in the benign category. Thyroid patients who underwent lobectomy, partial or total thyroidectomy were studied through histopathological examination. Biopsy reports were correlated with FNAC reports. Comparison of the present study with other previous study was shown in [Table 4]

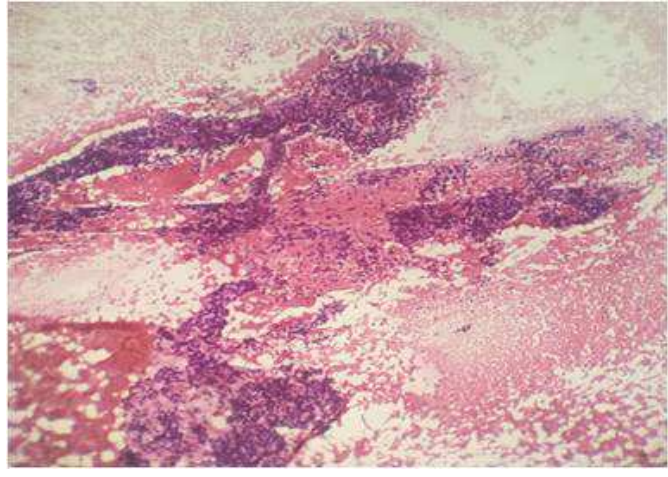

Fig-1: FNACx100- Papillary carcinoma thyroid

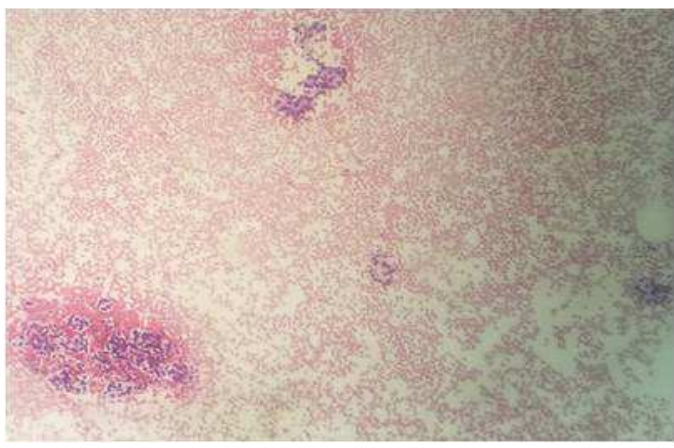

Fig-3: FNACx100- Follicular neoplasm

\section{Discussion}

Thyroid FNAC was initially started by Martin and Ellis in 1930. The terminology used for reporting thyroid FNAC has shown significant to avoid interlaboratory variations and discrepancies among different centers. Keeping this in view in 2007 , TBSRTC was evolved with the aim of forming a

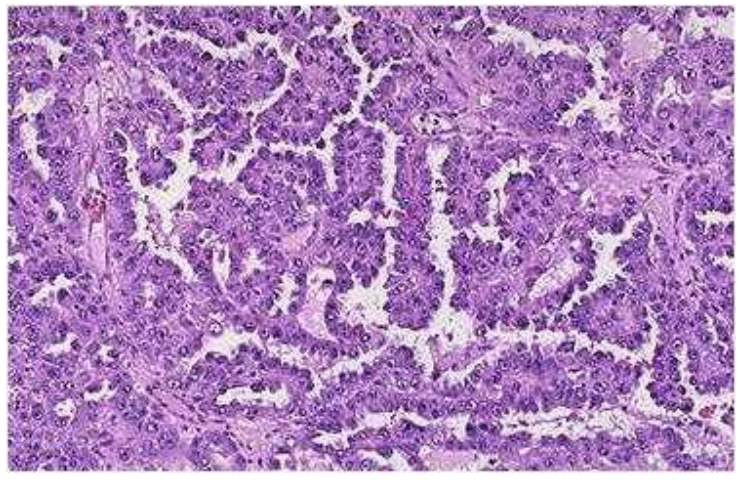

Fig-2: HPE x100-Papillary carcinoma thyroid

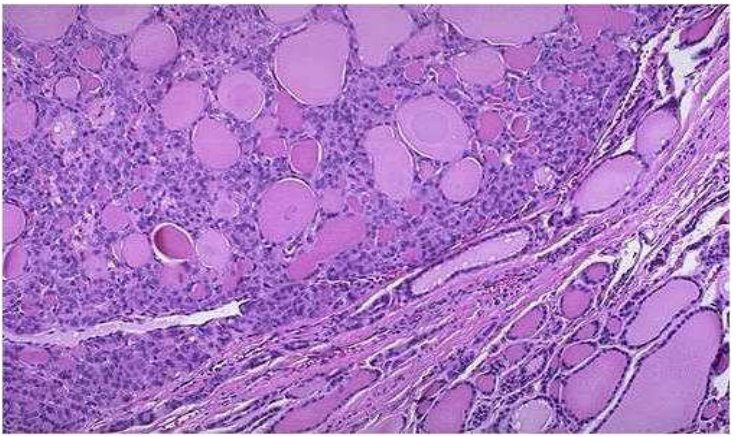

Fig-4: HPE x100- Follicular adenoma

uniformity in the reporting of thyroid that would facilitate effective discussion among cytopathologists and clinicians, correlation between cytology and histopathology, molecular genetics and diagnostic interpretation of thyroid diseases in particular neoplasia. 


\section{Original Research Article}

Palpable thyroid nodules are present in approximately $4-7 \%$ of adults and are more common in females with a $\mathrm{F}: \mathrm{M}$ ratio of $4.2: 1$. In the present study also there was a female predominance. In recent years, the role of FNAC is increasing regarding detection of thyroid nodules which are malignant. Early diagnosis is thus important for aiming at higher life expectancy especially since thyroid gland cancers have a low malignant potential and also have a slow progressive property.

Smears that are inadequate for reporting are categorized as non - diagnostic (ND) or unsatisfactory (UNS). Some nodules remain persistently ND/UNS even on repeat aspirations and should be subjected to surgical excision [6],[7]. As per the review of literature the rate of ND/UNS ranges between 16 to upto $20 \%$ [8,9]. In the present study, the rate of non- diagnostic tests was $5.33 \%$ [Table 3].Few authors suggest that the rate of nondiagnostic tests should be kept below 10\%. FNAC is a diagnostic role in most thyroid lesions especially for nodular colloid goiter, papillary carcinoma (PTC) and lymphocytic thyroiditis. For thyroid follicular carcinoma, smears are reported as follicular neoplasm (FN) or suspicious for a follicular neoplasm (SFN).

Various differentials in this category are follicular adenoma, follicular carcinomaand follicular variant of papillary carcinoma[10,11]. For definitive diagnosis of follicular carcinoma is done by histopathological examination which shows vascular and/or capsular invasion. About 35\% cases do not show any evidence of neoplasia but rather show hyperplastic proliferations of follicular cells as in multinodular goiter[12,13].The follicular variant of PTC mimics a benign follicular nodule on cytology because many a times the nuclear and architectural changes of some PTCs are patchy and not well discerned. As seen in literatures, the benign lesions represented the majority of cases. In our study benign lesions constituted 191 (84.89\%) cases. This is in accordance with previous studies.

The lesions included in the benign category were thyroglossal cyst, hyperplastic nodule of nodular colloid goiter and hashimotos thyroiditis. In the present study the sensitivity for cytological diagnosis of neoplasia was 99\%, specificity $100 \%$ and diagnostic accuracy of $99 \%$. Thus, showing a good positive correlation with histopathology. Various factors contribute to this wide range of sensitivity and specificity which is dependent on the adequacy of samples, technique of sample collection, the experience of the pathologist interpreting the smears, presence of overlapping cytological findings between some benign and malignant thyroid lesions and duration of follow up of the patient. FNAC has an overall accuracy rate of around $90-100 \%$ in the detection of thyroid malignancy [14] the present study showed a rate of $100 \%$. Any diagnostic procedures were actually having its own limitations and diagnostic fallacies.

It includes the presence of false negative(FNR) and false positive results (FPR). The lesions showing overlapping features for example microfollicular arrangements of the cells is difficult to distinguish nodular colloid goiter and follicular neoplasm with full accuracy[15].

FNR usually occur following sampling errors, coexistence of benign and malignant lesions, or due to presence of morphologic overlap between benign and low grade malignant tumors. These cases are of great importance more so since they indicate the potential of missing an underlying malignant pathology. FNR ranged from $1 \%$ to $16 \%$ in different series of publications and has been estimated to be usually less than 5\%. [16,17]. FNR can be reduced by proper follow-up and repeat aspiration to obtain adequate aspirates. FPR are less common and were not found in any patient in our study. This finding is consistent with the other reports that cited variable rates ranging from 09\%[18]. FPR are usually seen in cases of colloid nodule and nodular hyperplasia with numerous micropapillary structures and hashimotos thyroiditis. The sensitivity and specificity rate of thyroid FNAC as compared to histopathology may vary depending on the FNR, FPR and also on whether the suspicious cases are included in the negative or positive category. FNAC is still the procedure of choice, particularly if ultrasound is use as an ancillary technique for better sample collection although no single diagnostic method helps in providing a definitive diagnosis of cancer thyroid. However, errors can be reduced by obtaining multipleaspirates from different sites of the lesions using ultrasound- guided FNAC procedure and reviewing of slides by more than one cytopathologist. 


\section{Conclusion:}

FNAC is a remarkable tool in the management of thyroid lesions with a high degree of accuracy. It is safe, simple, cost-effective procedure. FNAC was performed without any complications and with good patients compliance.Non-aspiration technique of FNAC yielded better results in terms of cellularity with lesser obscuring effect of hemorrhage.Cytopathological correlation suggested sensitivity of $99 \%$ and specificity of $100 \%$. FNAC exhibits an adequate diagnostic correlation with the final histopathological examination. Hence FNAC gives definite diagnosis of various thyroid lesions either benign or malignant, therefore avoiding unnecessary thyroidectomies.

\section{What this study adds to existing knowledge?}

Suspicious cytologies make up to approximately $10 \%$ of aspirations. The thyroid cells on these aspirates are neither clearly benign nor malignant. $25 \%$ of suspicious lesions are found to be malignant when these patients undergo thyroid surgery. These are usually follicular or hurthle cell carcinoma. Therefore, surgery is recommended for the treatment of thyroid nodules from which a suspicious aspiration has been obtained.

\section{Contribution by authors}

Data collection and analysis was done by Dr. Venu Anand and Dr. Selvi, Manuscript was written by Dr. Venu Anand. The study was reviewed by all authors.

\section{Funding: Nil, Conflict of interest: None Permission of IRB: Yes}

\section{References}

1. Welker MJ, Orlov D. Thyroid nodules. Am Fam Physician. 2003 Feb 1;67(3):559-66.

2. Gharib H, Goellner JR.Fine-needle aspiration biopsy of the thyroid: an appraisal. Ann Intern Med. 1993 Feb 15;118(4):282-9.

3. Gupta M, Gupta S, Gupta VB. Correlation of fine needle aspiration cytology with histopathology in the diagnosis of solitary thyroid nodule. J Thyroid Res. 2010 Apr 18;2010:379051. doi: 10.4061/2010/379051.
4. Chandanwale S, Singh N, Kumar H, Pradhan P, Gore C, Rajpal M. Clinicopathological correlation of thyroid nodules. Int J Pharm Biomed Sci 2012; 3(3): 97-102.

5. Cibas ES, Ali SZ; NCI Thyroid FNA State of the Science Conference. The Bethesda System For Reporting Thyroid Cytopathology. Am J Clin Pathol. 2009 Nov; 132(5): 658-65. doi: 10.1309/ AJCPPHLWMI3JV4LA.

6. Yassa L, Cibas ES, Benson CB, Frates MC, Doubilet PM, Gawande AA, Moore FD Jr, Kim BW, Nosé V, Marqusee E, Larsen PR, Alexander EK. Long-term assessment of a multidisciplinary approach to thyroid nodule diagnostic evaluation. Cancer. 2007 Dec 25;111(6):508-16.

7. Nayar R, Ivanovic M. The indeterminate thyroid fine-needle aspiration: experience from an academic center using terminology similar to that proposed in the 2007 National Cancer Institute Thyroid Fine Needle Aspiration State of the Science Conference. Cancer. 2009 Jun 25;117 (3): 195-202. doi: 10.1002/cncy.20029.

8. Esmaili HA, Taghipour H. Fine-needle aspiration in the diagnosis of thyroid disease: An appraisal in our institution. ISRN Pathology [Internet]. 2012 Jun [cited 2012 Aug 2]; 912728: [about 4 p.]. Available from: http:// downloads. hindawi.com/journals/isrn.pathology/2012/912728.

9. Amrikachi M, Ramzy I, Rubenfeld S, Wheeler TM. Accuracy of fine-needle aspiration of thyroid. Arch Pathol Lab Med. 2001 Apr;125(4):484-8.

10. Baloch ZW, Livolsi VA. Follicular-patterned lesions of the thyroid: the bane of the pathologist. Am J Clin Pathol. 2002 Jan;117(1):143-50.

11. Deveci MS, Deveci G, LiVolsi VA, Baloch ZW. Fine-needle aspiration of follicular lesions of the thyroid. Diagnosis and follow-Up. Cytojournal. 2006 Apr 7;3:9. doi: 10.1186/1742-6413-3-9.

12. Baloch ZW, LiVolsi VA, Asa SL, Rosai J, Merino MJ, Randolph G, Vielh P, DeMay RM, Sidawy MK, Frable WJ. Diagnostic terminology and morphologic criteria for cytologic diagnosis of thyroid lesions: a synopsis of the National Cancer 
Institute Thyroid Fine-Needle Aspiration State of the Science Conference. Diagn Cytopathol. 2008 Jun; 36 (6):425-37. doi: 10.1002/dc.20830.

13. Yang J, Schnadig V, Logrono R, Wasserman PG. Fineneedle aspiration of thyroid nodules: A study of 4703 patients with histologic and clinical correlations. Cancer 2007;111:306-15.

14. Burch HB, Burman KD, Reed HL, Buckner L, Raber T, Ownbey JL. Fine needle aspiration of thyroid nodules: determination of insufficiency rates and malignancy yield at thyroidectomy. Acta Cytol 1996;40:1176-83.

15. Yassa L, Cibas ES, Benson CB, et al. Longterm assessment of multidisciplinary approach to thyroid nodule diagnostic evaluation. Cancer Cytopathol. 2007;111:508-516.
Original Research Article

16. Silverman JF, West RL, Larkin EW, Park HK, Finley JL, Swanson MS, Fore WW. The role of fine-needle aspiration biopsy in the rapid diagnosis and management of thyroid neoplasm. Cancer. 1986 Mar 15;57(6):1164-70.

17. Prakash HM, Jyothi BL, Shankar SH, Kishanprasad HL, Ramswamy AS, Aravinda P. Aspiration biopsy cytology of solitary thyroid nodule. NJBMS 2011;1(3):150-3.

18. Sengupta A, Pal R, Kar S, Zaman FA, Sengupta $\mathrm{S}$, Pal S. Fine needle aspiration cytology as the primary diagnostic tool in thyroid enlargement. $\mathrm{J}$ Nat Sci Biol Med. 2011 Jan;2(1):113-8. doi: 10.4103/0976-9668.82308.

\section{How to cite this article?}

Venu Anand, S. Selvi, B. Pushpa. A study of aspiration cytology of various thyroid lesions and histopathological correlation. Int J Med Res Rev 2017;5(11):943-948.doi:10.17511/ijmrr. 2017.i11.04 